Check for updates

Cite this: RSC Adv., 2017, 7, 22341

Received 10th January 2017

Accepted 13th April 2017

DOI: $10.1039 / \mathrm{c} 7 \mathrm{ra00389g}$

rsc.li/rsc-advances

\section{Facile synthesis of various epitaxial and textured polymorphs of vanadium oxide thin films on the (0006)-surface of sapphire substrates $\dagger$}

\author{
Bin Hong, ${ }^{a}$ Jiangtao Zhao, ${ }^{a}$ Kai Hu, ${ }^{a}$ Yuanjun Yang, (D) *abd Zhenlin Luo, ${ }^{\text {ab }}$ \\ Xiaoguang $\mathrm{Li}^{\mathrm{C}}$ and Chen Gao*ab
}

\begin{abstract}
Extensive attention has been paid to vanadium oxide polymorphs because of their potential to be used in applications in information and optoelectronic devices, as well as in energy harvesting technologies. However, vanadium oxides always form a very complex phase diagram; in particular, it is still challenging to synthesize pure vanadium oxide epitaxial polymorphs on low-cost, transparent and wafer-scale substrates. Here, we demonstrate the growth of epitaxial polymorphs of vanadium oxide $\left(\mathrm{VO}_{2}(\mathrm{R}, \mathrm{M} 1\right.$ and their mixed phase), and $\mathrm{V}_{2} \mathrm{O}_{3}$ ) and (001)-textured $\mathrm{VO}_{2}$ (B) thin films on the (0006) surface of sapphire without selecting specific substrate orientations. This is achieved by controlling the vanadium arrival rate via sputtering power and oxidation of vanadium atoms through the partial pressure of oxygen using magnetron sputtering techniques, which enables wafer-scale production of the vanadium oxide thin films on the sapphire substrates. Growth phase diagrams of the various polymorphs are also developed for guiding device design based on the vanadium oxide thin films. This work paves a way towards practical applications of vanadium oxide thin films on chemically stable, transparent and low-cost sapphire substrates.
\end{abstract}

\section{Introduction}

Transition metal oxides (TMOs) have attracted increasing research interest around the world ${ }^{\mathbf{1 - 3}}$ owing to their wide range of practical applications such as in field-effect transistors, ${ }^{4}$ optoelectronic devices, ${ }^{5}$ and memory devices. ${ }^{6}$ It is well known that TMOs always exhibit various polymorphic structures (e.g. multiferroic $\mathrm{BiFeO}_{3}$ thin films with tetragonal, rhombohedral, and monoclinic phases ${ }^{7}$ ) and are closely related to each other in a thermodynamic framework, which can lead to difficulties during synthesis, especially for thin film forms. ${ }^{\mathbf{8} 9}$ Analogous vanadium oxide is indeed one of the most complicated of the TMOs; it can exhibit various oxidation states (such as $\mathrm{V}^{2+}, \mathrm{V}^{3+}$,

${ }^{a}$ National Synchrotron Radiation Laboratory, Collaborative Innovation Center of Chemistry for Energy Materials, University of Science and Technology of China, Hefei, Anhui 230029, P. R. China. E-mail: yangyuanjun@ustc.edu.cn; cgao@ustc. edu.cn

${ }^{b}$ CAS Key Laboratory of Materials for Energy Conversion, Department of Materials Science and Engineering, University of Science and Technology of China, Hefei, Anhui 230026, P. R. China

${ }^{c}$ Department of Physics and Hefei National Laboratory for Physical Sciences at Microscale, University of Science and Technology of China, Hefei, Anhui 230027, P. R. China

${ }^{d}$ School of Electronic Science and Applied Physics, Lab of Quantum Materials and Interfaces, Hefei University of Technology, Hefei, Anhui 230009, P. R. China

$\uparrow$ Electronic supplementary information (ESI) available. See DOI: $10.1039 / \mathrm{c} 7 \mathrm{ra00389g}$
$\mathrm{V}^{4+}$, or $\mathrm{V}^{5+}$ ) and various crystal structures even with the same oxidation states. ${ }^{\mathbf{1 0 - 1 2}}$ For instance, vanadium dioxide $\left(\mathrm{VO}_{2}\right)$ has six or more polymorphs (e.g., R, M1, M2, A, B, C) with the same chemical formula.

Among these phases, monoclinic $\mathrm{VO}_{2}$ (M1) is the most widely studied owing to its abrupt metal-insulator transition (MIT) at around $68{ }^{\circ} \mathrm{C}$, coupled with a structural transition from a low-temperature monoclinic (M1 phase) to a hightemperature rutile ( $\mathrm{R}$ phase) structure. ${ }^{\mathbf{1 3 , 1 4}}$ The $\mathrm{VO}_{2}\left(\mathrm{M}_{2}\right.$ phase) polymorph is often observed as a metastable phase in the vicinity of the metal-insulator transition (MIT) of the $\mathrm{VO}_{2}$ (M1) nanowires and nanobeams. ${ }^{\mathbf{1 1}, 15,16} \mathrm{VO}_{2}(\mathrm{~A})$ is another metastable octahedrally coordinated phase composed of edge and cornersharing $\mathrm{VO}_{6}$ octahedra. The phase transition behavior is quite different from the $\mathrm{M} 1$ and $\mathrm{R}$ phase. $\mathrm{VO}_{2}$ (A) is transformed to the $\mathrm{R}$ phase, but this change is not reversible by changing the temperature. ${ }^{17} \mathrm{VO}_{2}$ (B) is also a metastable compound; it can be converted to a rutile or monoclinic structure after a suitable annealing process. ${ }^{8,18}$ Further, it is a promising material for energy applications, as it can be used as an electrode in Li-ion batteries. ${ }^{19,20}$ Meanwhile, $\mathrm{VO}_{2}$ (C) consists of layers of square $\mathrm{VO}_{5}$ pyramids, each of which shares its four basal edges with four neighboring square $\mathrm{VO}_{5}$ pyramids. ${ }^{21}$ The formation of these mixed and similar phases very often hinders the accurate understanding of the physical properties of the vanadium oxide polymorphs. Moreover, preparation of pure phases and highquality crystalline thin films has been a major challenge for 
vanadium oxide thin films and related device applications. An increasing number of studies on vanadium oxide have focused on epitaxial thin films, which can be grown using a variety of deposition techniques..$^{3,9,22-25}$ However, it is difficult to prepare pure vanadium oxides, especially thin films, of high crystalline quality because of the narrow range of the phase diagram, complex oxidation states of vanadium, and species diversity of the polymorphs (as mentioned above, there are at least six phases of $\mathrm{VO}_{2}$ ). Recently, Ho Nyung Lee and coworkers ${ }^{8}$ selectively grew tetragonal $\mathrm{VO}_{2}$ (A) on (011)-oriented $\mathrm{SrTiO}_{3}$ (STO) and $\mathrm{LaAlO}_{3}$ substrates, monoclinic $\mathrm{VO}_{2}$ (B) on a wide range of (001)-oriented perovskite substrates, and monoclinic $\mathrm{VO}_{2}$ (M1) on (111)-oriented STO, $\left(\mathrm{LaAlO}_{3}\right)_{0.3}\left(\mathrm{SrAl}_{0.5} \mathrm{Ta}_{0.5} \mathrm{O}_{3}\right)_{0.7}$ and $\mathrm{LaAlO}_{3}$ substrates using pulsed laser epitaxy. They also successfully grew epitaxial vanadium dioxide films of phase A, B, and M1 on (011), (001), and (111)-oriented STO substrates, respectively. ${ }^{26}$ Furthermore, T. Venkatesan et $a .^{27}$ grew high-quality single epitaxial films of tetragonal $\mathrm{VO}_{2}(\mathrm{~A})$, monoclinic $\mathrm{VO}_{2}$ (B), and $\mathrm{VO}_{2}$ (M1) thin films on (100)-oriented STO substrates using pulsed laser deposition.

Despite some recent progress in preparing vanadium oxide thin films, accessing vanadium oxide polymorphs generally depends upon using expensive substrates and carefully selecting different crystallographic orientations for different phases. In this work, we have successfully fabricated epitaxial thin films of vanadium sesquioxide $\left(\mathrm{V}_{2} \mathrm{O}_{3}\right)$ and various dioxide polymorphs ( $\mathrm{VO}_{2}(\mathrm{R}), \mathrm{VO}_{2}$ (M1), and $\mathrm{VO}_{2}$ (B)) on single cut (0006) sapphire surfaces using reactive ion magnetron sputtering. This technique enables wafer-scale production of vanadium oxide thin films. Moreover, the sapphire substrate $\left(\mathrm{Al}_{2} \mathrm{O}_{3}\right.$ crystal, normally several inches in size) is much cheaper than substrates such as STO or LAST. In addition, the sapphire substrate is so transparent in ultraviolet, visible and infrared regions that it can be used to design optoelectronic devices based on the vanadium oxide thin films.

\section{Experimental}

A vanadium metal disk in 2-in size was used as the sputtering target. The detailed growth conditions were presented and discussed in the main text. X-ray diffraction (XRD) was performed on Smartlab (Riguka, Japan) and partially on the 14B endstation in Shanghai synchrotron radiation facilities (SSRF). X-ray absorption spectroscopy (XAS) measurements were performed on the 08U in SSRF. We used inVia Raman microscope (Renishaw) to collect Raman spectra with a $532 \mathrm{~nm}$ laser. All the above measurements were finished at room temperature. The electrical transports were measured by physical property measurement system (Quantum Design).

\section{Results and discussion}

Fig. 1(a)-(d) shows the crystal structures with different symmetries of several typical vanadium oxides of $\mathrm{VO}_{2}(\mathrm{R}), \mathrm{VO}_{2}$ (B) $\mathrm{VO}_{2}$ (M1) and $\mathrm{V}_{2} \mathrm{O}_{3}$. To confirm the crystalline phases of the fabricated vanadium oxide thin films, X-ray diffraction (XRD) measurements were performed using a diffractometer equipped
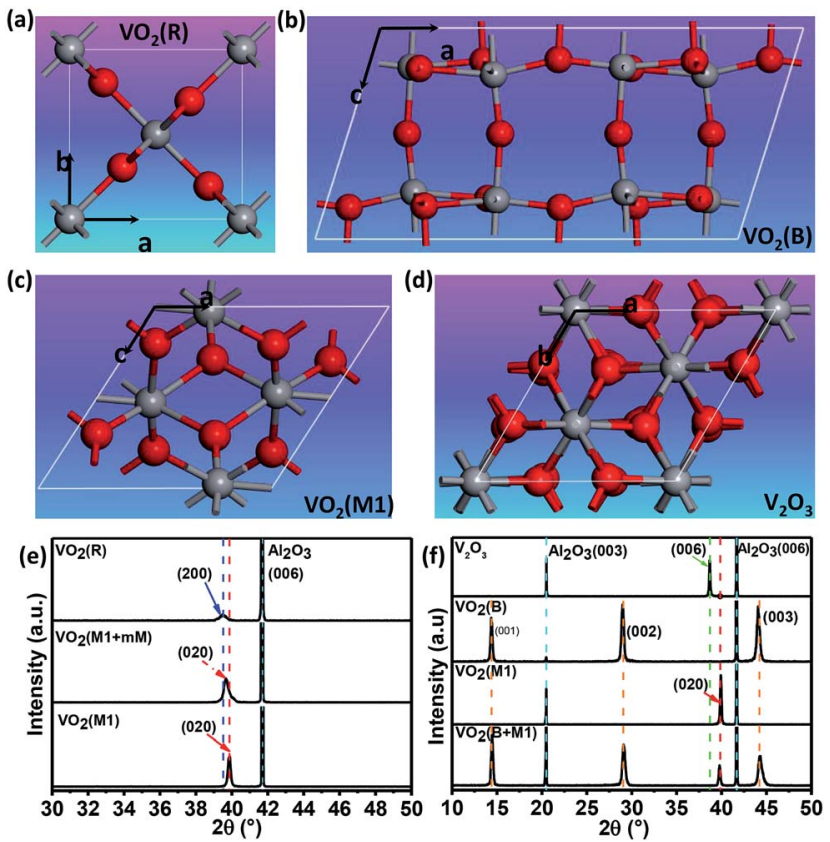

Fig. 1 Schematic crystal structures of (a) rutile $\mathrm{VO}_{2}(\mathrm{R})$, (b) monoclinic $\mathrm{VO}_{2}(\mathrm{M} 1)$, (c) monoclinic $\mathrm{VO}_{2}(\mathrm{~B})$, and (d) trigonal $\mathrm{V}_{2} \mathrm{O}_{3}$ phases. The red and gray spheres represent oxygen and vanadium atoms, respectively. (e) XRD patterns for $\mathrm{VO}_{2}$ (R), $\mathrm{VO}_{2}(\mathrm{M} 1+\mathrm{mM})$, and $\mathrm{VO}_{2}$ (M1). (f) XRD patterns for $\mathrm{V}_{2} \mathrm{O}_{3}(\mathrm{R}), \mathrm{VO}_{2}(\mathrm{~B}), \mathrm{VO}_{2}(\mathrm{M} 1)$, and the mixed-phase $\mathrm{VO}_{2}(\mathrm{~B})$ and $\mathrm{VO}_{2}(\mathrm{M} 1)$. XRD pattern of $\mathrm{VO}_{2}(\mathrm{M} 1)$ is re-plotted here for better comparison among different epitaxial polymorphs. All the films were grown to $120 \mathrm{~nm}$ (ref. 44) by controlling deposition time (please see the ESI, Fig. S $2 \uparrow$ ). The thicker films were chosen to minimize the substrate-induced strain effects.

with a Ge $(220) \times 2$ monochromator at a wavelength of $1.5406 \AA$. As shown in upper inset of Fig. 1(e), the characteristic (200) peak of the $\mathrm{VO}_{2}$ thin films occurs at about $39.5^{\circ}$ by $\theta-2 \theta$ scans, which is the feature of tetragonal phase (rutile phase). ${ }^{28}$ The corresponding lattice constant $a$ is determined to be $\sim 4.559 \AA$ and the out-of-plane lattice distortion $\left(a_{\text {bulk }}-a_{\text {film }}\right) / a_{\text {bulk }}$ is $-0.11 \%$. In the lower part of Fig. 1(e), the peak at $2 \theta=39.85^{\circ}$ is assigned to the (020) reflections of $\mathrm{VO}_{2}$ (M1). The series of the (001) reflections visible in Fig. $1(\mathrm{f})$ are assigned to the pure $\mathrm{VO}_{2}$ (B) phase. The interplane space in this $\mathrm{VO}_{2}$ (B) thin film is calculated to be $\sim 6.156 \AA$, which is in line with the previous reports. ${ }^{8}$ It is interesting that the mixed-phase $\mathrm{VO}_{2}(\mathrm{M} 1)$ and $\mathrm{VO}_{2}(\mathrm{mM}$, monoclinic metallic phase), and the mixed-phase $\mathrm{VO}_{2}$ (B) and $\mathrm{VO}_{2}$ (M1) were also fabricated as shown in the middle and lower part of Fig. 1(e) and (f). It's not hard to imagine that the interfaces between two different phases (e.g. $\mathrm{VO}_{2} \mathrm{M} 1$ and $\mathrm{B}$ phases) in the mixed-phase $\mathrm{VO}_{2}$ system would modulate the MIT behaviors, which is very interesting and need to be further studied. Moreover, the peak at $2 \theta=38.67^{\circ}$ in the XRD pattern is assigned to the (0006) peak of the $\mathrm{V}_{2} \mathrm{O}_{3}$ phase in the upper inset of Fig. 1(f). The diffraction peaks from the sapphire substrates are marked by dotted cyan lines for comparisons in Fig. 1(e) and (f). Moreover, in order to check the purities and orientations of different crystalline phases, the full scans of vanadium oxide thin films are shown in Fig. S1 (please see ESI $\dagger$ ). The above XRD analysis revealed that all vanadium oxide films with highly 
oriented growth habits are deposited on the single orientation on the (0006) sapphire substrates. Consequently, the desired and highly oriented vanadium oxide thin films can be grown on the single (0006) surface without changing the orientations of sapphire substrates through carefully controlling growth conditions.

To clarify the epitaxial behaviors, XRD phi scans of the typical vanadium oxide thin films were also performed. Fig. 2(a) shows that $\mathrm{V}_{2} \mathrm{O}_{3}$ could be grown on the (006) sapphire with following epitaxy relationship: (001) $\mathrm{V}_{2} \mathrm{O}_{3} / /(006) \mathrm{Al}_{2} \mathrm{O}_{3}$ and (100) $\mathrm{V}_{2} \mathrm{O}_{3} / /(100) \mathrm{Al}_{2} \mathrm{O}_{3}$. Fig. 2(b) shows that (010) $\mathrm{VO}_{2}$ (M1)//(006) $\mathrm{Al}_{2} \mathrm{O}_{3}$ and (100) $\mathrm{VO}_{2}$ (M1)//(100) $\mathrm{Al}_{2} \mathrm{O}_{3}$. However, the $\mathrm{VO}_{2}$ (B) film (110) peaks are hardly observed by XRD phi scans as demonstrated in Fig. 2(c), which is also in the cases of the (-401), (020) and (113) peaks (not shown here). Therefore, the $\mathrm{VO}_{2}$ (B) thin film on the (0006) surface of sapphire favors the (001)-textured growth as similar as on the (001) surface of $\mathrm{SrTiO}_{3}$ substrate. ${ }^{29}$ This result is likely due to the in-plane random stacking of the 2-dimensional $\mathrm{V}-\mathrm{O}$ layers.

In order to further confirm crystal structures of the above phases, Raman spectroscopy was utilized to study lattice dynamics and thus discriminate the these various vanadium oxide phases. The Raman spectra of several typical vanadium oxide at room temperature are shown in Fig. 2(d). Raman peaks at around 417, 499, and $749 \mathrm{~cm}^{-1}$ (marked by the dashed red lines) in Fig. 2(d) are assigned to the $\mathrm{Al}_{2} \mathrm{O}_{3}$ substrate. The Raman spectra of $\mathrm{V}_{2} \mathrm{O}_{3}$ exhibits prominent low-frequency modes at around 212, 230, and $294 \mathrm{~cm}^{-1}$ at room temperature, which is in agreement with results in previous studies. ${ }^{30}$ The three representative Raman peaks at around 193, 223, and $614 \mathrm{~cm}^{-1}$ correspond to the $\mathrm{VO}_{2} \mathrm{M} 1$ phase, and the peak positions also agree well with literature values. ${ }^{31-34}$ However, no Raman peaks was observed in the metallic $\mathrm{VO}_{2}$ rutile phase and thus displays almost no Raman activity in line with the ref. 35. And the $\mathrm{VO}_{2}$ (B) thin film has the three typical vibrating modes at 159, 266 and $415 \mathrm{~cm}^{-1}$, which was also reported by Lee et al. ${ }^{8}$
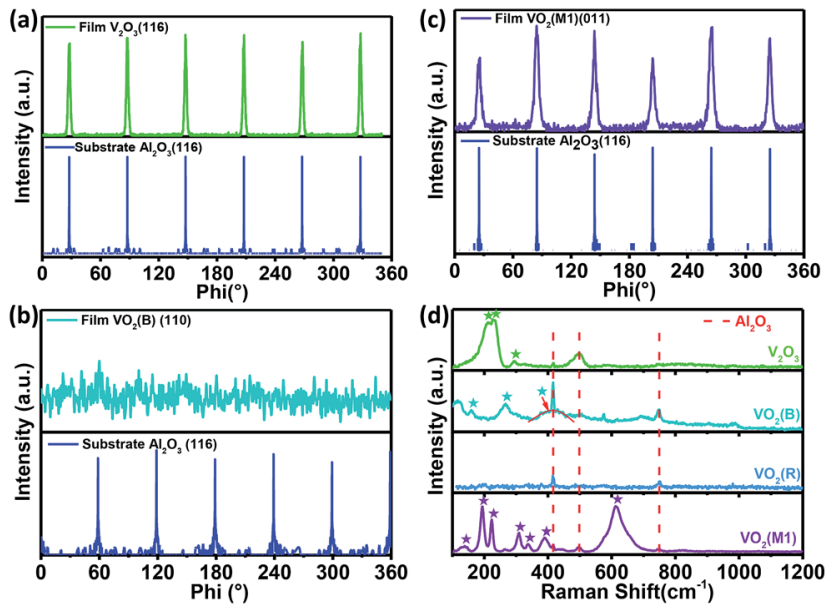

Fig. 2 Phi scans of different vanadium oxide epitaxial thin films. (a) $\mathrm{V}_{2} \mathrm{O}_{3}$. (b) $\mathrm{VO}_{2}(\mathrm{M1})$, and (c) $\mathrm{VO}_{2}$ (B). (d) Raman spectra of different epitaxial polymorphs of $\mathrm{VO}_{2}$ and $\mathrm{V}_{2} \mathrm{O}_{3}$ thin films. The Raman peaks at around 417, 499, and $749 \mathrm{~cm}^{-1}$ (marked by the dashed red lines) are assigned to the $\mathrm{Al}_{2} \mathrm{O}_{3}$ substrate.
Since the surface microstructures are very important for designing thin-film devices, the various vanadium dioxide polymorphs and $\mathrm{V}_{2} \mathrm{O}_{3}$ epitaxial thin films were investigated by atomic force microscopy (AFM). In topographical terms, both the $\mathrm{VO}_{2}(\mathrm{~B}+\mathrm{M} 1)$ and $\mathrm{VO}_{2}$ (B) films in Fig. 3(d) and (e) exhibit a larger grain size than the $\mathrm{VO}_{2}(\mathrm{R})$ and $\mathrm{V}_{2} \mathrm{O}_{3}$ films in Fig. 3(a) and (f). We noted that a relatively large proportion of the selforganized domain patterns separate out from the matrix of thin films in the $\mathrm{VO}_{2}(\mathrm{M} 1+\mathrm{mM})$ phase (shown in Fig. 3(b)). Meanwhile, the pure $\mathrm{VO}_{2}$ (M1) in Fig. 4(c) shows that a continuous film is normally formed as reported in ref. 24 and 36.

Based on the above characterizations, the vanadium oxide epitaxial polymorphs can be obtained as what one wants. By varying the power of the radio-frequency (RF) supply, argon and oxygen flow ratio, we could change the arrival rate of the atoms on the surface of the sapphire substrates. Moreover, by adjusting the oxygen flow rate and growth temperature, we could also change the oxidation of vanadium on the substrates. We found that the phase of the vanadium oxide thin films is more sensitive to the growth temperature with low oxygen flow levels (below $1.0 \mathrm{sccm}$, set argon flow of $50.6 \mathrm{sccm}$, and RF power of 60 $\mathrm{W})$. We also found that the critical growth temperature is $\sim 490^{\circ} \mathrm{C} . \mathrm{VO}_{2}$ (R) was produced with low oxygen flow and at low temperature (oxygen flow $<1.0 \mathrm{sccm}$ and temperature below 490 ${ }^{\circ} \mathrm{C}$ ), while $\mathrm{VO}_{2}$ (M1) was produced above the critical temperature of $\sim 490{ }^{\circ} \mathrm{C}$. Table 1 summarizes the crystal structure, lattice constants and optimized growth conditions for the pure $\mathrm{VO}_{2}$ (R), $\mathrm{VO}_{2}(\mathrm{M} 1), \mathrm{VO}_{2}$ (B) phases and $\mathrm{V}_{2} \mathrm{O}_{3}$ on the (0006)-oriented sapphires, respectively.

Consequently, we were able to construct a simple phase diagram for growing the different vanadium oxide polymorphs (shown in Fig. 2(a)) based on the effects of oxygen flow and growth temperature in Fig. 4(a). Moreover, we further confirmed the validity of the growth phase diagram for vanadium oxides, which is found to correlate well with RF power and oxygen flow rate. In Fig. 4(b), a richer phase diagram for the growth conditions is presented. This guides us in studying the effect of RF power and the oxygen flow on the stability of the metastable phase $\mathrm{VO}_{2}(\mathrm{~B})$, which has not been realized in the pure thin film single phase form on the (0006)-oriented sapphire substrates so far. $\mathrm{V}_{2} \mathrm{O}_{3}$ was fabricated at a low oxygen flow rate $(<1.0 \mathrm{sccm})$, which was hardly impacted by changing the RF power. However, $\mathrm{RF}$ power could seriously influence the $\mathrm{VO}_{2}$ (B) and $\mathrm{VO}_{2}$ (M1) phases at higher oxygen flow rates. Additionally, when the oxygen flow rate was over $3.0 \mathrm{sccm}$, we obtained the $\mathrm{VO}_{2}$ polymorph, which is a mixed-phase system of $\mathrm{VO}_{2}(\mathrm{~B})$ and $\mathrm{VO}_{2}$ (M1). This mixed-phase system has also not been reported previously. It is mentionable that both the metastable regions in Fig. 4(a) and (b) represent the ghost phases, which have not been understood well so far. Fig. 4(c) shows the photograph of (010)$\mathrm{VO}_{2}$ (M1) epitaxial thin films on the 2-inch-size sapphire substrate. Moreover, the prices of the sapphire and other substrates for the depositions of the $\mathrm{VO}_{2}$ thin films are listed in the Table S1 (please see ESI $\dagger$ ) for comparison. The electrical transport properties of the various polymorphs of the vanadium oxide epitaxial thin films and textured (001)- $\mathrm{VO}_{2}$ (B) thin films were measured, and the corresponding results are shown in 
(a)

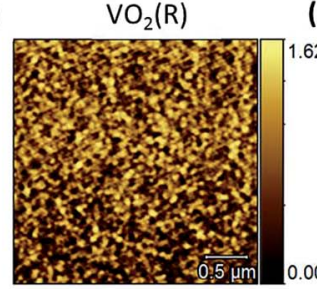

(d)

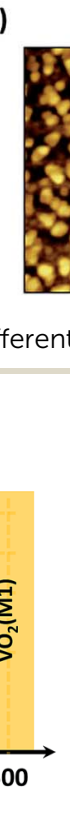

$\mathrm{VO}_{2}(\mathrm{~B}+\mathrm{M} 1)$

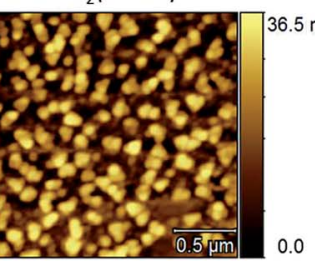

(b)

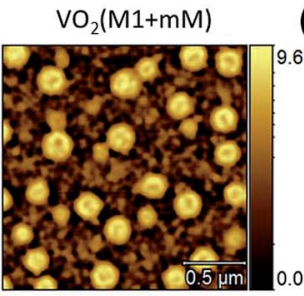

(e)

$\mathrm{VO}_{2}(\mathrm{~B})$

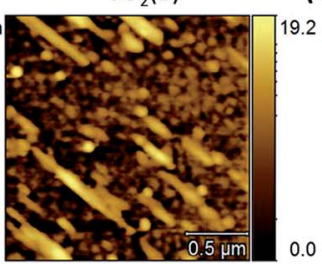

(c)

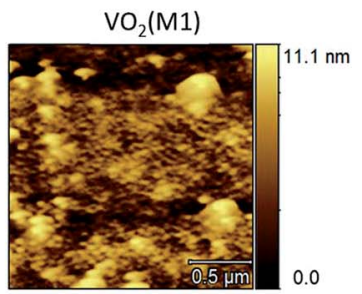

(f)

(f) $\quad \mathrm{V}_{2} \mathrm{O}_{3}$

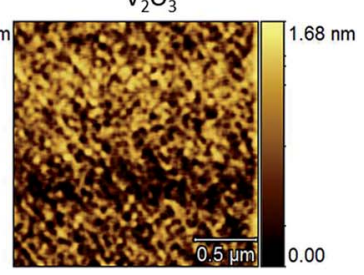

Fig. 3 AFM images for the different $\mathrm{V}_{2} \mathrm{O}_{3}$ and $\mathrm{VO}_{2}$ epitaxial polymorphs on the (0006)-oriented sapphire substrates.

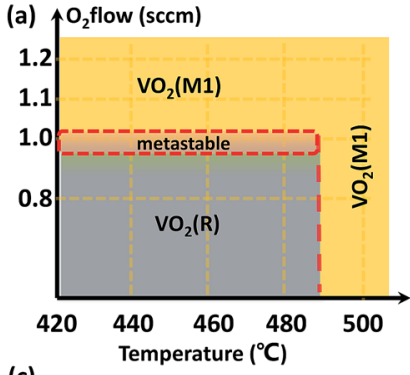

(c)

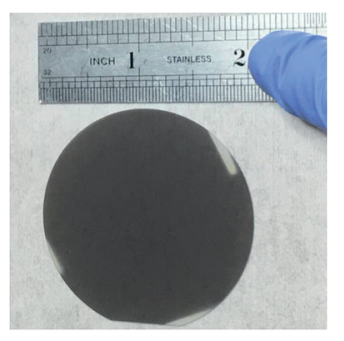

(b) $\uparrow \mathrm{O}_{2}$ flow (sccm)

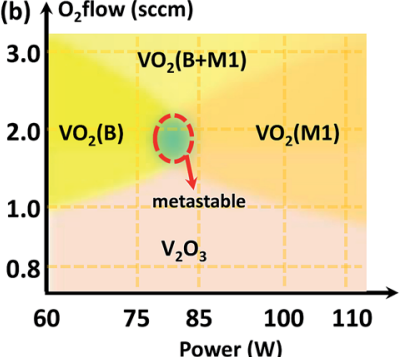

(d)

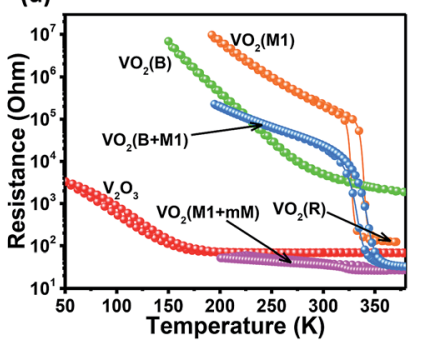

Fig. 4 Phase diagram for different polymorphs of vanadium oxide thin films with growth temperature and oxygen flow (a), and RF power and oxygen flow (b). (c) The wafer scale production of $\mathrm{VO}_{2}$ epitaxial polymorphs in $\mathrm{M} 1$ phase. (d) Transport properties of different epitaxial polymorphs of $\mathrm{VO}_{2}$ and $\mathrm{V}_{2} \mathrm{O}_{3}$ epitaxial thin films.

Fig. 4(d). The $\mathrm{VO}_{2}$ (M1) phase is semiconducting, and its temperature-dependent resistivity is in good agreement with our previous results, ${ }^{36}$ which also gives the MIT critical

temperature as $\sim 340 \mathrm{~K}$. It is mentionable that the reversibility of the MIT has been demonstrated very well experimentally. ${ }^{26-28,36}$ However, the $\mathrm{VO}_{2}$ (B) phase is a semimetal at room temperature, which still exhibits a change of four orders of magnitude in resistivity from 380 to $150 \mathrm{~K}$ during the cooling and heating cycles without any hysteresis. Unlike the electrical transport properties of the $\mathrm{VO}_{2}(\mathrm{M} 1)$ or $\mathrm{VO}_{2}(\mathrm{~B})$ phase, the $\mathrm{V}_{2} \mathrm{O}_{3}$ phase is a metal at room temperature and a semimetal at low temperatures (with hysteresis), which may be associated with the MIT. ${ }^{37,38}$ The two mixed-phase systems $\mathrm{VO}_{2}(\mathrm{mM}+\mathrm{M} 1)$ and $\mathrm{VO}_{2}(\mathrm{~B}+\mathrm{M} 1)$ thin films also show a MIT, likely due to the dominations of M1 phases over the other phases. However, the MIT is subtle and obviously suppressed in comparison to the pure M1 phase. The detailed MIT behaviors of these novel phases will be further studied in the future.

To further study the essence of the different vanadium oxide polymorph phases, their electronic structures were studied by $\mathrm{X}$-ray absorption spectroscopy (XAS) at the V L-edge (2p) and $\mathrm{O}$ K-edge (1s) at room temperature, which allowed us to determine the nature of the unoccupied states in the conduction band. We found that there were two peaks at around 514.9 and $517.6 \mathrm{eV}$ in the insulating phase $\left(\mathrm{VO}_{2}\right.$ (M1)), as shown in Fig. 5(a), which correspond to the transitions from the $\mathrm{V} 2 \mathrm{p}_{3 / 2}$ core-level to $t_{2 g}\left(d_{\|}^{*}\right)$ and $e_{g}\left(\sigma^{*}\right),,^{39-41}$ respectively. For the semimetal phase $\left(\mathrm{VO}_{2}(\mathrm{~B})\right)$, we also observed that the main peak was located at approximately $517.5 \mathrm{eV}$ with a satellite peak $(\sim 515.1 \mathrm{eV})$. For the metallic phase $\left(\mathrm{VO}_{2}(\mathrm{R})\right.$ and $\left.\mathrm{V}_{2} \mathrm{O}_{3}\right)$, we did not observe any

Table 1 Crystal structures and optimal growth conditions for vanadium oxide polymorphs

\begin{tabular}{|c|c|c|c|c|c|c|c|c|}
\hline \multirow{2}{*}{$\begin{array}{l}\text { Vanadium oxide } \\
\text { polymorphs }\end{array}$} & \multirow[b]{2}{*}{ Crystal structure } & \multicolumn{4}{|c|}{ Lattice constants in bulk } & \multicolumn{3}{|c|}{ Growth condition } \\
\hline & & $a(\AA)$ & $b(\AA)$ & $c(\AA)$ & $\beta$ or $\gamma\left(^{\circ}\right)$ & Temp $\left({ }^{\circ} \mathrm{C}\right)$ & $\mathrm{Ar}: \mathrm{O}_{2}(\mathrm{sccm})$ & Power $(\mathrm{W})$ \\
\hline $\mathrm{VO}_{2}-\mathrm{R}$ & $\mathrm{P4}_{2} / \mathrm{mnm}$ & 4.554 & 4.554 & 2.855 & 90 & $400-480$ & $50.6:(0.5-1.0)$ & 60 \\
\hline $\mathrm{VO}_{2}-\mathrm{M} 1$ & $P 2_{1} / c$ & 5.752 & 4.526 & 5.382 & 122.6 & $\begin{array}{l}400-500 \\
490\end{array}$ & $\begin{array}{l}50.6:(1.0-1.2) \\
60.0:(1.0-2.8)\end{array}$ & $\begin{array}{l}60 \\
80-120\end{array}$ \\
\hline $\mathrm{VO}_{2}-\mathrm{B}$ & $C 2 / m$ & 12.03 & 3.69 & 6.42 & 106.6 & 490 & $60.0:(1.0-3.0)$ & $50-80$ \\
\hline $\mathrm{V}_{2} \mathrm{O}_{3}$ & $R \overline{3} c$ & 4.951 & 4.951 & 14.004 & $\gamma=120$ & 490 & $60.0:<1.0$ & $50-120$ \\
\hline
\end{tabular}



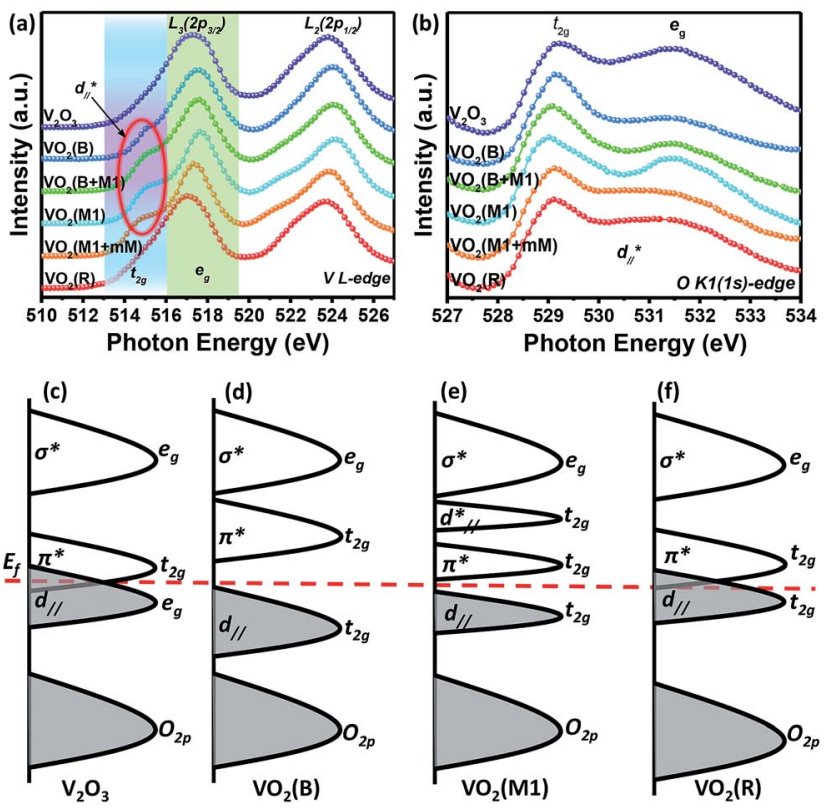

Fig. 5 X-ray absorption spectroscopy (XAS) of $\mathrm{V} \mathrm{L} \mathrm{(a)} \mathrm{and} \mathrm{O} \mathrm{K} \mathrm{(b)} \mathrm{edges}$ in the various epitaxial vanadium oxide polymorphs. Diagrams illustrate the electronic structures of $\mathrm{V}_{2} \mathrm{O}_{3}$ in (c), $\mathrm{VO}_{2}$ (B) in (d), $\mathrm{VO}_{2}(\mathrm{M} 1)$ in (e), and $\mathrm{VO}_{2}(\mathrm{R})$ in $(\mathrm{f})$ in terms of Goodenough's rules.

obvious satellite peaks at room temperature. The O K1-edge XAS results for vanadium oxide are shown in Fig. 5(b). There are also two peaks at 529.1 and $531.5 \mathrm{eV}$, which correspond to the transitions from the $\mathrm{O} 1 \mathrm{~s}$ core-level to the unoccupied $\mathrm{t}_{2 \mathrm{~g}}$ and $\mathrm{e}_{\mathrm{g}}$ levels, respectively. The line shapes of these peaks resemble each other. However, the spectral weighting of each differs, which will be studied in future. According to the above electronic structure studies and Goodenough's rule, ${ }^{23,42,43}$ schematics of the band structures of the different vanadium oxides are proposed as shown in Fig. 5(c)-(f). The metallic behaviors in Fig. 5(c) and (f) are found in $\mathrm{V}_{2} \mathrm{O}_{3}$ and $\mathrm{VO}_{2}$ (R) because the Fermi level lies in the conduction band. However, the band gaps are open in $\mathrm{VO}_{2}$ (B) and $\mathrm{VO}_{2}$ (M1) at room temperature in Fig. 5(d) and (e), respectively, which is why they are insulating. Therefore, it is observed that a shift of the unoccupied $t_{2 g}$ orbitals away from the Fermi level is a common feature that plays an important role in the insulating behavior of $\mathrm{VO}_{2}$ polymorphs.

\section{Conclusions}

To summarize, we first presented growth phase diagrams of the vanadium oxide polymorphs and achieved the growth of epitaxial polymorphs of vanadium oxide thin films $\left(\mathrm{VO}_{2}(\mathrm{R}), \mathrm{VO}_{2}\right.$ (M1), and $\mathrm{V}_{2} \mathrm{O}_{3}$ ) and (001)-textured $\mathrm{VO}_{2}$ (B) on the single (0006)cut sapphire substrates using reactive ion magnetron sputtering techniques. The nature of the phases in the different polymorphs was determined using X-ray diffraction and Raman spectroscopy. Additionally, the electrical transport properties were measured to confirm the phases of the vanadium oxide thin films. We also compared the electronic structures of the electronically insulating $\left(\mathrm{VO}_{2}\right.$ (M1)), semimetal $\left(\mathrm{VO}_{2}\right.$ (B)), and metal $\left(\mathrm{VO}_{2}(\mathrm{R})\right.$ and $\left.\mathrm{V}_{2} \mathrm{O}_{3}\right)$ phases using synchrotron radiation Xray absorption. Consequently, we developed growth phase diagrams by controlling the sputtering power, argon and oxygen flow rate, and substrate temperature. Moreover, the crystal and electronic structural comparisons of the various vanadium oxide phases provide insights for a better understanding of the electronic structure and the origin of insulating gap in $\mathrm{VO}_{2}$. This work paves the way toward facile fabrication of high-quality vanadium oxide epitaxial polymorphs on low-cost commercial sapphire substrates without changing the substrate orientation, thereby allowing for wafer scale production.

\section{Author contributions}

Yuanjun Yang and Chen Gao conceived the idea of this work. Yuanjun Yang and Bin Hong designed the experiments of this work. Jiangtao Zhao, Bin Hong, Kai Hu and Yuanjun Yang performed XRD and data analysis. Raman spectra were measured by Jiangtao Zhao and Bin Hong. Yuanjun Yang and Bin Hong performed AFM studies and analyzed the data. XAS was carried out by Bin Hong, Kai Hu and Yuanjun Yang. The paper was written by Bin Hong. Yuanjun Yang, Zhenlin Luo, Xiaoguang Li and Chen Gao discussed the results. All authors reviewed this manuscript.

\section{Conflict of interest}

The authors declare no competing financial interest.

\section{Acknowledgements}

This work was mainly supported by the National Natural Science Foundation of China (51402281, U1632273) and National Key Research and Development Program of China (No. 2016YFA0300102), and partially supported by the Anhui Natural Science Foundation (1508085QA06). We gratefully acknowledge Lijuan Zhang and Renzhong Tai for the electronic structure characterizations at the BL08U1A beamline of the Shanghai Synchrotron Radiation Facility (SSRF), and Wensheng Yan at the magnetic circular dichroism endstation of the National Synchrotron Radiation Laboratory (NSRL). This work was partially carried out at the USTC Center for Micro and Nanoscale Research and Fabrication, and we also thank Jinlan Peng, Xiaolei Wen, and Linjun Wang for their help with the AFM measurements.

\section{Notes and references}

1 E. Dagotto, Science, 2005, 309, 257-262.

2 Z. Yang, C. Ko and S. Ramanathan, Annu. Rev. Mater. Res., 2011, 41, 337-367.

3 A. P. Peter, K. Martens, G. Rampelberg, M. Toeller, J. M. Ablett, J. Meersschaut, D. Cuypers, A. Franquet, C. Detavernier, J. P. Rueff, M. Schaekers, S. Van Elshocht, M. Jurczak, C. Adelmann and I. P. Radu, Adv. Funct. Mater., 2015, 25, 679-686. 
4 N. Shukla, A. V. Thathachary, A. Agrawal, H. Paik, A. Aziz, D. G. Schlom, S. K. Gupta, R. Engel-Herbert and S. Datta, Nat. Commun., 2015, 6, 7812.

5 M. Nakano, K. Shibuya, N. Ogawa, T. Hatano, M. Kawasaki, Y. Iwasa and Y. Tokura, Appl. Phys. Lett., 2013, 103, 153503.

6 T. Driscoll, H. T. Kim, B. G. Chae, B. J. Kim, Y. W. Lee, N. M. Jokerst, S. Palit, D. R. Smith, M. Di Ventra and D. N. Basov, Science, 2009, 325, 1518-1521.

7 R. J. Zeches, M. D. Rossell, J. X. Zhang, A. J. Hatt, Q. He, C. H. Yang, A. Kumar, C. H. Wang, A. Melville, C. Adamo, G. Sheng, Y. H. Chu, J. F. Ihlefeld, R. Erni, C. Ederer, V. Gopalan, L. Q. Chen, D. G. Schlom, N. A. Spaldin, L. W. Martin and R. Ramesh, Science, 2009, 326, 977-980.

8 S. Lee, I. N. Ivanov, J. K. Keum and H. N. Lee, Sci. Rep., 2016, 6, 19621.

9 Y. D. Ji, T. S. Pan, Z. Bi, W. Z. Liang, Y. Zhang, H. Z. Zeng, Q. Y. Wen, H. W. Zhang, C. L. Chen, Q. X. Jia and Y. Lin, Appl. Phys. Lett., 2012, 101, 071902.

10 C. Wu, F. Feng and Y. Xie, Chem. Soc. Rev., 2013, 42, 51575183.

11 M. Nazari, Y. Zhao, Z. Y. Fan, K. Ziemer, A. A. Bernussi and M. Holtz, J. Phys. D: Appl. Phys., 2015, 48, 135101.

12 C. Wang, X. Liu, J. Shao, W. Xiong, W. Ma and Y. Zheng, RSC Adv., 2014, 4, 64021-64026.

13 F. J. Morin, Phys. Rev. Lett., 1959, 3, 34-36.

14 L. Chen, X. Wang, D. Wan, Y. Cui, B. Liu, S. Shi, H. Luo and Y. Gao, RSC Adv., 2016, 6, 73070-73082.

15 V. R. Morrison, R. P. Chatelain, K. L. Tiwari, A. Hendaoui, A. Bruhacs, M. Chaker and B. J. Siwick, Science, 2014, 346, 445-448.

16 H. Asayesh-Ardakani, W. Yao, A. Nie, P. M. Marley, E. Braham, R. F. Klie, S. Banerjee and R. ShahbazianYassar, Appl. Phys. Lett., 2017, 110, 053107.

17 L. Bai, Q. Li, S. A. Corr, Y. Meng, C. Park, S. V. Sinogeikin, C. Ko, J. Wu and G. Shen, Phys. Rev. B: Condens. Matter Mater. Phys., 2015, 91, 104110.

18 X. J. Wang, H. D. Li, Y. J. Fei, X. Wang, Y. Y. Xiong, Y. X. Nie and K. A. Feng, Appl. Surf. Sci., 2001, 177, 8-14.

19 X. Xia, D. Chao, C. F. Ng, J. Lin, Z. Fan, H. Zhang, Z. X. Shen and H. J. Fan, Mater. Horiz., 2015, 2, 237-244.

20 H. Liu, Y. Wang, K. Wang, E. Hosono and H. Zhou, J. Mater. Chem., 2009, 19, 2835.

21 D. Hagrman, J. Zubieta, C. J. Warren, L. M. Meyer, M. M. J. Treacy and R. C. Haushalter, J. Solid State Chem., 1998, 138, 178-182.

22 B. D. Ngom, M. Chaker, A. Diallo, I. G. Madiba, S. Khamlich, N. Manyala, O. Nemraoui, R. Madjoe, A. C. Beye and M. Maaza, Acta Mater., 2014, 65, 32-41.

23 N. B. Aetukuri, A. X. Gray, M. Drouard, M. Cossale, L. Gao, A. H. Reid, R. Kukreja, H. Ohldag, C. A. Jenkins, E. Arenholz, K. P. Roche, H. A. Dürr, M. G. Samant and S. S. P. Parkin, Nat. Phys., 2013, 9, 661-666.

24 R. E. Marvel, R. R. Harl, V. Craciun, B. R. Rogers and R. F. Haglund, Acta Mater., 2015, 91, 217-226.
25 S. Lee, T. L. Meyer, S. Park, T. Egami and H. N. Lee, Appl. Phys. Lett., 2014, 105, 223515.

26 S. Lee, T. L. Meyer, C. Sohn, D. Lee, J. Nichols, D. Lee, S. S. A. Seo, J. Freeland, T. Noh and H. N. Lee, APL Mater., 2015, 3, 126109.

27 A. Srivastava, H. Rotella, S. Saha, B. Pal, G. Kalon, S. Mathew, M. Motapothula, M. Dykas, P. Yang, E. Okunishi, D. D. Sarma and T. Venkatesan, APL Mater., 2015, 3, 026101.

28 H. Qiu, M. Yang, Y. Dong, H. Xu, B. Hong, Y. Gu, Y. Yang, C. Zou, Z. Luo and C. Gao, New J. Phys., 2015, 17, 113016.

29 A. P. Chen, Z. X. Bi, W. R. Zhang, J. Jian, Q. X. Jia and H. Y. Wang, Appl. Phys. Lett., 2014, 104, 071909.

30 N. Kuroda and H. Y. Fan, Phys. Rev. B: Condens. Matter Mater. Phys., 1977, 16, 5003-5008.

31 S. J. Chang, J. B. Park, G. Lee, H. J. Kim, J. B. Lee, T. S. Bae, Y. K. Han, T. J. Park, Y. S. Huh and W. K. Hong, Nanoscale, 2014, 6, 8068-8074.

32 C. Marini, E. Arcangeletti, D. Di Castro, L. Baldassare, A. Perucchi, S. Lupi, L. Malavasi, L. Boeri, E. Pomjakushina, K. Conder and P. Postorino, Phys. Rev. B: Condens. Matter Mater. Phys., 2008, 77, 235111.

33 A. M. Makarevich, I. I. Sadykov, D. I. Sharovarov, V. A. Amelichev, A. A. Adamenkov, D. M. Tsymbarenko, A. V. Plokhih, M. N. Esaulkov, P. M. Solyankin and A. R. Kaul, J. Mater. Chem. C, 2015, 3, 9197-9205.

34 Q. Yu, W. Li, J. Liang, Z. Duan, Z. Hu, J. Liu, H. Chen and J. Chu, J. Phys. D: Appl. Phys., 2013, 46, 055310.

35 M. Pan, J. Liu, H. Zhong, S. Wang, Z.-f. Li, X. Chen and W. Lu, J. Cryst. Growth, 2004, 268, 178-183.

36 M. Yang, Y. Yang, B. Hong, L. Wang, Z. Luo, X. Li, C. Kang, M. Li, H. Zong and C. Gao, RSC Adv., 2015, 5, 80122-80128. 37 B. S. Allimi, S. P. Alpay, C. K. Xie, B. O. Wells, J. I. Budnick and D. M. Pease, Appl. Phys. Lett., 2008, 92, 202105.

38 L. Dillemans, T. Smets, R. R. Lieten, M. Menghini, C. Y. Su and J. P. Locquet, Appl. Phys. Lett., 2014, 104, 071902.

39 T. C. Koethe, Z. Hu, M. W. Haverkort, C. SchüßlerLangeheine, F. Venturini, N. B. Brookes, O. Tjernberg, W. Reichelt, H. H. Hsieh, H. J. Lin, C. T. Chen and L. H. Tjeng, Phys. Rev. Lett., 2006, 97, 116402.

40 M. Abbate, F. M. F. de Groot, J. C. Fuggle, Y. J. Ma, C. T. Chen, F. Sette, A. Fujimori, Y. Ueda and K. Kosuge, Phys. Rev. B: Condens. Matter Mater. Phys., 1991, 43, 72637266.

41 L. Whittaker, J. M. Velazquez and S. Banerjee, CrystEngComm, 2011, 13, 5328.

42 M. W. Haverkort, Z. Hu, A. Tanaka, W. Reichelt, S. V. Streltsov, M. A. Korotin, V. I. Anisimov, H. H. Hsieh, H. J. Lin, C. T. Chen, D. I. Khomskii and L. H. Tjeng, Phys. Rev. Lett., 2005, 95, 196404.

43 S. Kumar, J. P. Strachan, M. D. Pickett, A. Bratkovsky, Y. Nishi and R. S. Williams, Adv. Mater., 2014, 26, 7505-7509.

44 B. Hong, K. Hu, Z. Tao, J. Zhao, N. Pan, X. Wang, M. Lu, Y. Yang, Z. Luo and C. Gao, Phys. Rev. B: Condens. Matter Mater. Phys., 2017, 95, 075433. 